parallel the Freudian distinction between an "underlying neurosis" and its symptoms. Consequently behaviour therapy consists essentially in the application of theories of learning.

Experiments on learning have shown a variety of ways in which responses may be changed, diminished, or eliminated. Each suggests an analogous method of treating neurotic symptoms. One example is the method of "strengthening incompatible responses," or " reciprocal inhibition," as Wolpe describes it. A simple illustration would be that of a child who, afraid of dogs, is given a puppy. The puppy is sufficiently unlike a grown dog to elicit the fear to a slight degree only. Its antics evoke pleasurable responses, and as the puppy grows into a dog the pleasurable responses spread gradually to all dogs.

Another method, aversive conditioning, is frequently employed when the symptom to be treated is some form of antisocial behaviour such as a sexual perversion. Painful stimulation, produced by electrical or pharmacological means, is applied while the patient behaves in the undesirable manner and is discontinued when this form of behaviour ceases. The time relations are important in this method of treatment and make it different from normal punishment procedures.

As yet only the simpler generalizations of learning theory have been applied in behaviour therapy, and there is some advantage in this. For though important principles, such as those concerned with the time relations in aversive therapy, must not be violated, the principles can be grasped without a technical knowledge of the complexities of contemporary experimental psychology. Many of these methods are therefore available to the general practitioner, who may well find them useful in dealing with mildly neurotic patients who do not justify referral to a psychiatrist. Learning theory, however, is relevant not only to simple forms of behaviour but also to complex verbal and social behaviour and even modes of thinking. Undoubtedly future developments will increase the complexity and sophistication of behaviour therapy.

Already the literature contains reports of the apparently successful treatment of a wide range of neurotic conditions, including phobias, hysteria, sexual disorders, tics, and tension states. The majority are concerned with the treatment of relatively isolated symptoms, or related groups of symptoms, in highly co-operative patients whose anxieties and neurotic reactions are reactive to aspects of the environment which can be altered by the therapist. Few

1 Behaviour Research and Therapy. Edited by H. J. Eysenck. Pergamon Press, Oxford.

Wolpe, J., Psychotherapy by Reciprocal Inhibition. Stanford University Press. 1958.

Behaviour Therapy and the Neuroses, 1960. Edited by H. J. Eysenck. Oxford. accounts exist of the behavioural treatment of all the ramifications of the neurotic personality. But there is little evidence that this form of treatment, being symptomatic, is superficial and liable to aggravate the patient's general condition or produce substitute symptoms. The few evaluative studies are encouraging though they lack controls. Behaviour therapy is now at the stage where large-scale and well-controlled clinical trials are necessary to explore its proper uses further.

\section{METALS AND LIVER DISEASE}

A relationship between certain metals in the body and hepatic cirrhosis has long been recognized in two of the less common varieties of liver disease-iron in haemochromatosis (bronze diabetes), ${ }^{1}$ and copper in Wilson's disease (hepato-lenticular degeneration). ${ }^{2}$ Cirrhosis due to chronic poisoning with arsenic is now extremely rare and likely to arise only as a result of excessive therapy with organic or inorganic arsenicals.

The main difficulty hitherto in detecting a relationship between hepatic disease and the presence of trace metals was the lack of sufficiently sensitive tests for the metals. The introduction of neutron activation analysis ${ }^{3}$ has remedied this, for it can detect heavy metals in quantities as small as $10^{-9} \mathrm{~g}$. The principle of the method is relatively simple. A dried sample of the tissue is exposed to bombardment by neutrons in a nuclear reactor. The elements under investigation are then separated by standard microchemical techniques and their radioactivity acquired from the neutron bombardment is estimated. The quantity of the element present is then calculated by comparison with the radioactivity acquired by a pure sample of the same element that was simultaneously exposed in the nuclear reactor.

In the B.M.J. this week Mr. A. H. Hunt and his colleagues report (page 1498) that in such a study of liver samples from 450 cases of hepatic cirrhosis they found a strikingly high concentration of copper in six patients with primary biliary cirrhosis. The mean concentration of copper was 30 times that found in normal controls and almost twice the level found in Wilson's disease. If. as is generally held, the cirrhosis of Wilson's disease is a toxic effect of the retained copper, the higher level of copper found in these patients with biliary cirrhosis must also be accepted as hepatotoxic. Though the retention of copper in the liver in biliary cirrhosis may possibly be a secondary result of the

\footnotetext{
Sheldon, J. H., Haemochromatasis. 1935. Oxford Untversity Press, London. 2 Glazebrook, A. J., Edinb. med. J., 1945, 52, 83.

3 Parr. R. J., and Taylor. D. M., Phys. in Med. Biol., 1963, 8, 43.

- Herbert. P. A., and Tamaki, H. T., Amer, J, clin. Path, 1946, 16, 640.

5 MacDonald, R. A., Arch. intern. Med.. 1961, 107, 606.

Woldman, E. E.. Fishman, D., and Segal, A. J., J. Amer. med. Ass., 1959. 169. 1281.

7 MacDonald, R. A., and Mallory, O. K., Arch. intern. Med., 1960, 105, 686.
} 
obstruction, since the bile is the main route for the excretion of copper, this is rendered unlikely by the findings of Hunt and his colleagues that in cases of longstanding extra-hepatic biliary obstruction the amount of copper in the liver was only about twice the normal. But in this type of case reabsorption of copper by the bile duct's mucosa and excretion via the kidney might explain the lower level of hepatic copper. Measuring the copper content of the liver in cases of long-standing viral hepatitis (in which the anatomical level of biliary obstruction is presumably about the same as in idiopathic biliary cirrhosis) should help to answer this question.

In a group of 18 cases of non-biliary cirrhosis studied by Hunt and his colleagues the mean content of iron $(282 \mu \mathrm{g} . / \mathrm{g}$.) was not significantly greater than normal $(183 \mu \mathrm{g} / \mathrm{g}$.$) . However, other workers have obtained$ different figures ${ }^{4}$-figures which led Drs. Sheila Callender and J. S. Malpas to study the absorption of iron in patients with cirrhosis. Their findings are reported in the B.M.J. this week at page 1516. In nine cirrbotic patients, despite an abnormally high level of serum iron, the absorption of iron from the bowel was significantly increased whether administered as inorganic ferrous sulphate or as rabbit haemoglobin. In the absence of adequate information about the mechanism normally controlling the absorption of iron it is impossible to explain where the defect lies in these cirrhotics. The effect of giving pancreatic extracts with the test doses of iron did, however, produce some highly suggestive results. In each instance the absorption of iron was diminished. Pancreatic deficiency in patients with cirrhosis of the liver has been described by other observers $^{6}$ " and may therefore, as suggested by Callender and Malpas, be causing the excessive uptake of iron they detected.

The possibility that patients with cirrhosis of the liver have an abnormally high uptake of heavy metals, as shown by Callender and Malpas for iron, and as suggested by the figures of Hunt and his colleagues for copper, raises another question of some importance. Does the increase of heavy metals in the liver have anything to do with the fact that primary carcinoma is commoner in cirrhotic than non-cirrhotic livers? This increase of malignant hepatomas has been reported from many centres and is confirmed by the latest figures from St. Thomas's Hospital reported by Drs. S. G. Elkington, D. J. McBrien, and H. Spencer at page 1501 of the B.M.J. In a series of 7,366 necropsies performed in the 23 years from 1940 to 1962 inclusive there were 39 cases of primary hepatic carcinoma and 157 cases of cirrhosis. Thirty of the carcinomata developed in association with cirrhosis, an incidence of $19 \%$, the remaining 9 occurring amongst the 7,209 non-cirrhotic cases, an incidence of $0.125 \%$. The incidence in the cirrhotic livers was therefore 152 times that in the noncirrhotic livers. Data at present available are insufficient to justify any firm conclusions, but Hunt and his colleagues are undoubtedly correct in concluding that "the role of minute quantities of heavy metals in the aetiology of certain types of cirrhosis may be appreciable. Their part in the causation of cancer of the liver remains to be investigated."

\section{MILROY'S DISEASE AND LYMPHOEDEMA}

Oedema caused by obstruction of the lymphatics may be secondary to neoplasm, trauma, or infection. In primary lymphoedema the cause of lymphatic obstruction is not evident and cases may be classified arbitrarily as congenital (present at birth), praecox (onset before $35)$, and late.

W. F. Milroy ${ }^{1}$ described a family in which 22 of 97 members in six generations had chronic oedema of one or both legs. The swelling had been present from birth in all cases except one. The condition was compatible with longevity and good health. Further examples of hereditary oedema were described by E. E. Letessier, ${ }^{2}$ M. Nonne, ${ }^{3}$ and $\mathrm{H}$. Meige. ${ }^{4}$ Hence the complex eponym Nonne-Milroy-Meige's disease. However, most cases of chronic lymphoedema of the legs are neither familial nor congenital. In one series of 300 cases of chronic lymphoedemas 105 were primary : twelve of these were congenital but none was familial; the remaining 93 were praecox. In another 107 cases, reported by J. B. Kinmonth and colleagues, ${ }^{6} 12$ were congenital, 82 were praecox, and 13 of late onset. In this series 18 were familial and only 2 both familial and congenital. Thus only about $1 \%$ of cases of primary lymphoedema are true examples of Milroy's disease-that is, are both hereditary and congenital.

\footnotetext{
Milroy, W. F., N.Y. med. J., 1892. 56, 505

(a) Strasbourg, 1865, quoted by Schroeder and Helweg-Larsen.21

3 Nonne, M., Virchows Arch. path. Anat., 1891, 125, 189.

4 Meige, H., Presse mid., 1898, 6. 341.

Allen, E. V. Barker, N. W.. and Hines, E. A., Peripheral Vascular Diseases, 3rd ed.. 1962, p. 690. Saunders, Philadelphia and I ondon.

Kinmonth. J. B., Taylor. G. W., Tracy, G. D., and Marsh, J. D., Brit. J. Surg. $1957,45,1$.

7 Hope, W. B., and French, H., Quart. J. Med., 1908, 1, 312.

- Hagy, G. W... and Danhof. I., Amer. J. hum. Genet., 1958, 10, 141.

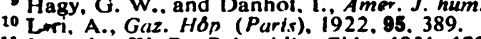

11 Jaroschy, W. B., Britr. klin. Chir. 1931, i52, 632

12 Weber. F. P., and Schititer, A.. Proc. roy. Soc. Med., 1937, 30, 933.

13 Bloom. D., N.Y. Si. J. Med. i941. 41. 856.

14 Polani, P. E.. Brit. med. Bulli, 1961, 17, 200.

18 Jones, H. E., Arih. Dis. Childh. 1960, 35, 192.

16 Gough. M. H. Guiney, E. J. and Kinmo

10 Jennett. J. H.. Clin. Orihop., 1956. 8. 122.

19 McGuire. J.. and Zeek. P.. J. Amer. med. Ass. 1932, 88, 870.

20 Radner, S., Acra derm.-venereol. (Srockh.), 1946, 26, 261.

Schroeder, E., and Helweg-l.arsen. H.. d.to med scand. 1950, 137,198

${ }^{2}$ Cockayne. E. A.. Inhorited Ahnormalities of the Skin and its Appenduges, 1933 p. 375. Oxford Univ. Prens. London.

Barker. N. W.. Carey, B.. and Brough, W., Minn. Med.. 1959, 42, 227.

24 Dencker, S. J., and Gott ries. I.. Aclu med. scand. 1954, 150, 277.

23 Panos. T. C.. J. Amer. med. Ass.. 1956, 161. 1475.

22 Kowlem, R., B-it. J. plast. Surg.. 1948. 1, 48. Simeone, F. A., 1962, p. 363 . London.
} 